\title{
EDITORIAL
}

\section{Promoting socio-economic equity in South Asia}

\author{
Siri Hettige
}

Department of Sociology, Faculty of Arts, University of Colombo, Colombo, Sri Lanka.

Chairman-Working Committee on Social Sciences, National Science Foundation, Colombo, Sri Lanka.

South Asian countries, despite recent social and economic changes in the region, continue to be characterised by deep rooted social and economic inequalities. While there are significant intra-regional and intra-country variations in the above regard, poverty and inequalities continue to affect the life chances of millions of South Asians. Moreover, economic inequalities based on the distribution of income and other economic assets, manifested in diverse of deprivation, dissemination and marginalisation, also characterise much of South Asia. Some of the long standing inequalities are intricately connected to caste, gender, ethnic and religious differences.

It is against the above background that, in 2015, a regional conference on Promoting Socio-Economic Equity in South Asia: Challenges and Prospects (ICPSE), was held in Colombo, organised jointly by the Indian Council of Social Science Research and the National Science Foundation of Sri Lanka, with the support of the UNDP. Many papers from a number of South Asian countries dealing with diverse sub-themes connected with the overall theme of the conference were presented by eminent scholars from the participating countries. The papers included in this special issue of Sri Lanka Journal of Social Sciences were also presented at the above conference. These papers have been selected following the standard review process adopted by the Editorial Board of the Journal. The areas covered by the papers published have varied widely including quality improvement of university education, impact of war on children, floriculture industry of Sri Lanka, transcending ethno-religious differences, disability and poverty, and women empowerment through income generation.

The first article by Chandra Gunawardena analyses the Quality Assurance Agency Council reviews of both academic programmes offered by various Sri Lankan University Departments and the institutional quality of Universities. The second article on war-affected children by Kumari Thoradeniya examines how the concepts of psycho-social and psycho-social programmes emerged and are conducted in relation with such children. Following this, Padmini, S. M. P. C. and Kodagoda, T. D., in their article, examine the present status and the scope of Sri Lanka's floriculture industry and its ability to empower women in the surveyed parts of the country. In the fourth article, Anton Piyarathne looks at the Kataragama PadaYatra in Sri Lanka (a religiocultural event) and its potential role in transcending ethno-religious boundaries. P. H. T. Kumara and D. N. B. Gunewardena, in their article, examine the nexus between disability and poverty in Sri Lanka in the light of empirical data collected and analysed by them. Finally, in the last article in this issue, M. A. M. I. Perera and M. Wijeratne investigate the relationship between remittances and rural primary education in Sri Lanka by way of a case study conducted by the authors. 